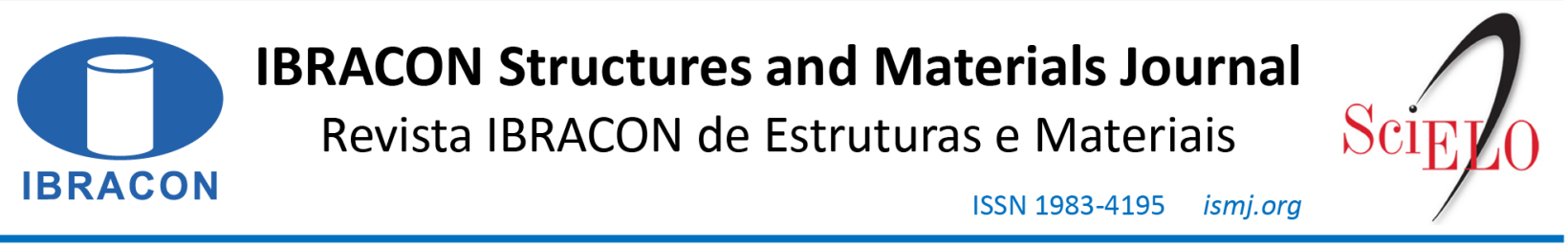

ORIGINAL ARTICLE

\title{
Numerical analysis of reinforced concrete shear walls with rectangular cross section
}

\section{Análise numérica de pilares-parede de concreto armado com seção retangular}

\author{
Maurício Castelo Branco de Noronha Campos ${ }^{\mathrm{a}}$ (i) \\ Paulo Marcelo Vieira Ribeiro ${ }^{\mathrm{b}}$ (i) \\ Romilde Almeida de Oliveira ${ }^{\mathrm{c}}$
}

${ }^{a}$ Universidade Estadual do Piauí - UESPI, Centro de Tecnologia e Urbanismo, Teresina, Piauí, Brasil

${ }^{\text {b} U n i v e r s i d a d e ~ F e d e r a l ~ d e ~ P e r n a m b u c o ~-~ U F P E, ~ C e n t r o ~ d e ~ T e c n o l o g i a ~ e ~ G e o c i e ̂ n c i a s, ~ R e c i f e, ~ P E, ~ B r a s i l ~}$

${ }^{c}$ Universidade Católica de Pernambuco - UNICAP, Centro de Ciências e Tecnologia, Recife, PE, Brasil

Received 03 April 2019

Accepted 12 May 2020

\begin{abstract}
This study addresses a numerical analysis of reinforced concrete columns in which the lengths are significantly larger than their widths with a rectangular cross section. Numerical simulations of 1,440 cases were performed, each case simulated with the single bar model, isolated bar model and mesh model, in addition, 3D model simulations were carried out. For the validation of $3 \mathrm{D}$ models and bar models, comparisons were made between the numerical simulation e experimental results of 24 reinforced concrete columns. Second order effects were analyzed on the vertical moment at the edge of the columns in which the lengths are significantly larger than the widths (localized second-order effects) and also the values of the horizontal moments along the cross sectional length in the mesh model. Influences of the main variables were observed influencing the behavior of the columns in which the lengths are significantly larger than their widths: the ratio between the cross sectional dimensions, the slenderness and the stresses (normal stress and bending moment around the axis of greatest inertia).
\end{abstract}

Keywords: shear walls, numerical analysis, nonlinear analysis, localized second-order effects.

Resumo: Neste trabalho foi feita uma análise numérica de pilares-parede de concreto armado com seção transversal retangular. Foram feitas simulações numéricas de 1.440 casos, onde cada caso foi simulado com o modelo de barra única, com o modelo de barras isoladas e com o modelo de malha, além disso, foram feitas simulações em modelos 3D. Para a validação dos modelos 3D e modelos de barra foram feitas comparações entre as simulações e resultados experimentais de 24 pilares de concreto armado. Foram analisados os efeitos de segunda ordem no momento vertical na extremidade do pilar-parede (efeitos localizados de segunda ordem) e também os valores dos momentos horizontais ao longo do comprimento da seção transversal no modelo com malha. Após as simulações numéricas foram feitas análises dos efeitos de segunda ordem no momento fletor ao longo da altura dos pilares-parede e dos momentos fletores na direção do comprimento da seção, observando as influências das principais variáveis que determinam o comportamento dos pilares-parede a relação entre as dimensões da seção transversal, a esbelteza e os esforços solicitantes (esforço normal e momento fletor em torno do eixo de maior inércia).

Palavras-chave: pilar-parede, análise numérica, análise não linear, efeitos localizados de segunda ordem.

How to cite: M. C. B. N. Campos, P. M. V. Ribeiro, and R. A. Oliveira, "Numerical analysis of reinforced concrete shear walls with rectangular cross section," Rev. IBRACON Estrut. Mater., vol. 13, no. 6, e13614, 2020, https://doi.org/10.1590/S1983-41952020000600014

\section{INTRODUCTION}

Shear walls are structural elements in which the cross sections are normally rectangular or consisting of rectangles where one of the dimensions is larger than the other, resulting in a column with an open or shut section with a slender wall. In accordance with ABNT NBR 6118:2014 [1], columns with a larger dimension of the cross section five times 
more than the smaller dimension $(b>5 \mathrm{~h}$ ) are called shear walls. Cross sections of shear walls can be single, rectangular, or consisting of two or more rectangles, having as a result sections in the shape of $\mathrm{C}, \mathrm{T}, \mathrm{L}$ and $\mathrm{H}$, with high axial rigidity and high bending strength.

Similar to ABNT NBR 6118:2014 [1], the majority of international standards (for example, ACI-318 [2] and MC10 [3]) classify shear walls only according to the geometry as a result of the ratio between the sizes of the cross section, without considering the importance of the different effects from the existing demands.

Normally, shear walls act as bracing structures of the building and are placed in staircases and elevator shafts of tall buildings. They withstand both horizontal (due to wind or earthquakes) and gravitational loads.

According to Campos [4], the three key points to be observed when analyzing and sizing shear walls are: first, the distribution of the overall horizontal forces on the structural elements comprising the building; secondly, how these overall forces are absorbed by the cross section, and lastly, the possibility of localized effects.

Reinforced concrete shear walls with slender wall cross sections, when undergoing mainly compressive strengths due to the bending moment around the axis of greater inertia, are subject not only to localized effects along the stretch between cross bracing, but to concentrated effects at the ends of their cross section. These effects are termed by ABNT NBR 6118:2014 [1] as localized second order effects, see Figure 1.

The problem of buckling in concrete cross sections is more frequent now, mainly due to evolution of concrete technology, which has successfully produced stronger materials, resulting in cross sections with very high slenderness, which was not common in the shear walls of older buildings, when the strength of concrete used was not so high and, consequently, the cross sections were thicker, and therefore much more robust than those used today.
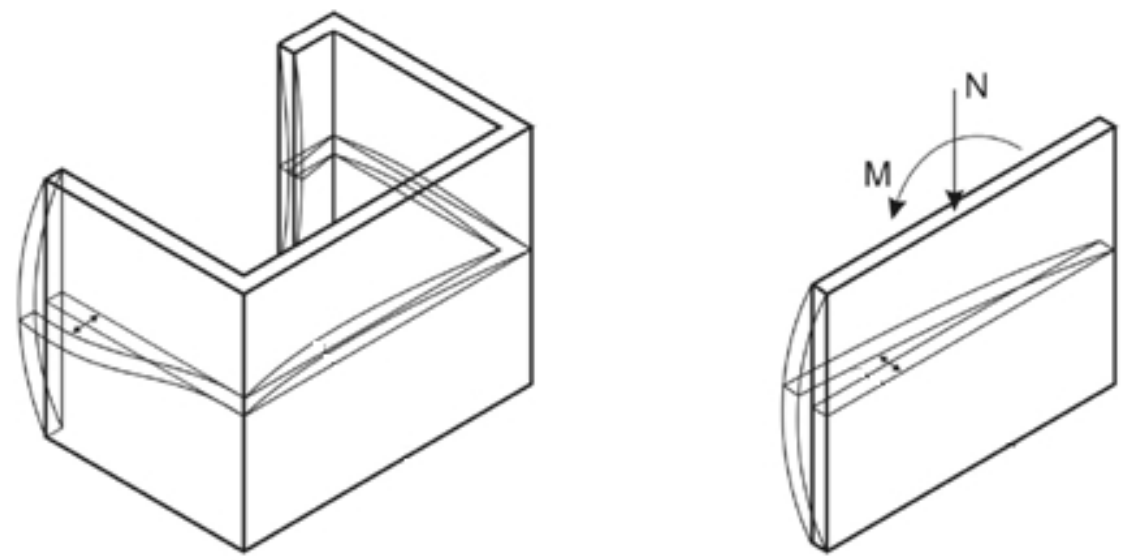

Figure 1. Localized second order effects (ABNT NBR 6118:2014 [1])

According to Wallace and Moehle [5], because of the significant progress in construction and design practice over the last 30 years and in order to optimize savings and safety, engineers made several modifications to the shear wall design boundaries. These modifications resulted in slimmer profiles undergoing stricter requirements that were confirmed in most laboratory tests or field experiments.

Failure due to buckling was observed in some laboratory tests (e.g., Thomsen and Wallace [6]. Detailed surveys carried out as part of the ATC-94, apud Wallace and Moehle [5], indicate that overall buckling of the wall was not caused by the shift in reinforcement (as had been initially suspected based on earlier studies), but instead, was a result of lateral instability of previously crushed edges.

Parra and Moehle [7] found two buckling mechanisms in the shear walls. The first occurs after the end of the shear wall had undergone a tensile plastic deformation that causes fissuring and, consequently, reduced rigidity. The second buckling mechanism begins with the detachment of the concrete from the reinforcement cover, resulting in a relatively slender core that tends to buckle. They conclude that the buckling mechanism is a form of secondary failure, which occurs after the reduction in rigidity of the end of the shear wall.

According to Wight and MacGregor [8], the main factors to be considered in the design of structural walls are the following: the structural function of the wall in relation to the rest of the structure, the wall may be supported and 
clamped to the structure, or the wall may act as a support and bracing for the rest of the structure; the types of load that the wall withstands; and the quantity and positioning of reinforcement in the cross section of the wall.

Based on the 2003 version, ABNT NBR 6118 implemented an item (15.9) specifically addressing the sizing of shear walls. In this item, ABNT NBR 6118:2014 [1] determines that: "In order for shear walls to be able to be included as linear elements in the resistant assembly of the structure, it should be guaranteed that their cross section keeps its shape by proper bracing on the different floors and that the local second order effects are duly assessed".

The local second order effects in shear walls must be analyzed in the same way as the conventional columns $(b \leq 5 \mathrm{~h})$ and the localized second order effects may be considered according to an approximate process in which the shear wall is broken down into vertical strips that must be analyzed as separate columns. This approximate process of ABNT NBR 6118 was criticized in the technical sector, mainly with regard to analyzing the strips as if they were separate columns, since it is a situation very different from reality.

Campos [4] states that another item that has created lively discussion in the technical field is the quantity of transverse reinforcement in shear walls required by ABNT NBR 6118 since the edition in 2003. This transverse reinforcement is designed to combat buckling of the longitudinal reinforcement rods and to withstand the forces of horizontal bending from the localized second order effects.

In other international standards, namely, for example, ACI-318 [2] and MC10 [3], there is no reference to the consideration of the localized second order effects in the sizing of shear walls. However, the Brazilian situation is quite different from the rest. One of the major differences between what happens abroad and in Brazil is the occurrence of earthquakes. In Brazil, the main horizontal loading acting on buildings comes from wind force, contrary to what occurs in other countries, where the horizontal loading of the wind is secondary and the main horizontal demand originates in seismic waves.

This difference in loadings is reflected in the applied forces and, consequently, in how the shear walls are treated. Table 1 shows the sizes of the cross sections and the values of the dimensionless normal force of the shear walls analyzed by Araújo [9], França and Kimura [10], Arnott [11], Sritharan et al. [12], where a huge difference is found in the values of the design dimensionless normal force $\left(v_{d}\right)$.

Table 1. Sections Dimensions and dimensionless normal force

\begin{tabular}{ccccc}
\hline & b $(\mathbf{c m})$ & $\mathbf{h}(\mathbf{c m})$ & $\mathbf{b} / \mathbf{h}$ & $\mathbf{v}$ \\
\hline Araújo [9] & 360 & 20 & 18 & 0.88 \\
\hline França and Kimura [10] & 300 & 20 & 15 & 0.68 \\
\hline Anott [11] & 600 & 20 & 30 & 0.04 \\
\hline Sritharan et al. [12] & 229 & 15 & 15 & 0.00 \\
\hline
\end{tabular}

Figure 2 shows the horizontal shake map in different parts of the world. The range of colors varies from white to brown, where the white represents the regions with low shake values and the brown representing regions with peak shake values.

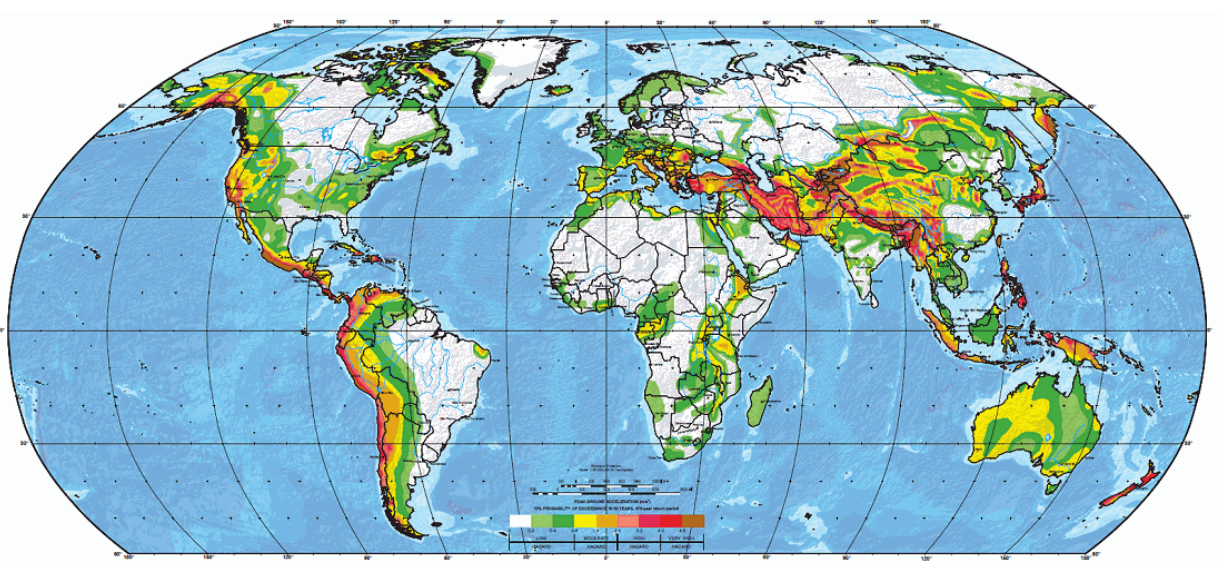

Figure 2. World horizontal shake map (http://www.maparelieve.com) 
ABNT NBR 15421:2006 [13] sets the minimum requirements for checking the safety of the usual structures in civil construction in relation to the seismic actions and quantifying criteria of such actions and the strengths to be considered in the design of buildings' structures. To define the seismic actions to be considered in a design, this standard divides Brazil into five seismic zones (due to the design shake characteristic - g), as shown in Figure 3.

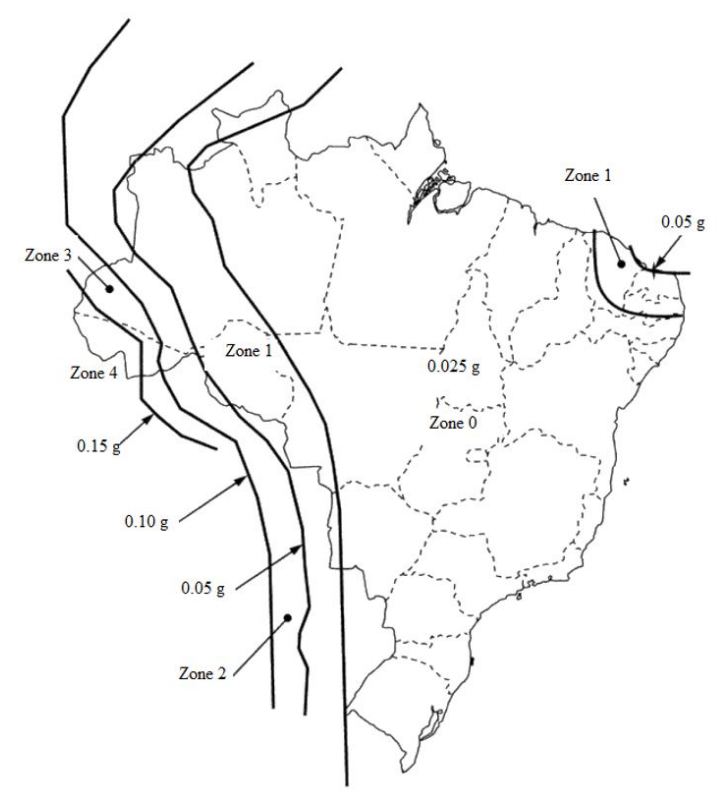

Figure 3. Characteristic horizontal shake map of Brazil (ABNT NBR 15421:2006)

Pursuant to item 7.3.1 of ABNT NBR 15421:2006 [13], for structures located in the seismic zone 0 there is no requirement of seismic resistance. Figure 3 shows that most Brazilian territory is within the seismic zone 0 , especially the most densely populated regions and, therefore, with a higher quantity of buildings and where the highest are located, which are those that most suffer the effects of horizontal loads.

The region comprising the States of Ceará, Rio Grande do Norte and Paraíba has a relatively high population density (especially in the capitals) and are outside the seismic zone 0 . This region is practically all within a seismic zone 1 where, and despite being necessary, low intensity seismic effects are considered since the value of the characteristic design shake is 0.025-0.05 (g). This is why the loading referring to seismic action in Brazil is not as important as in other countries.

\subsection{Justification}

Shear walls are structural elements very often used in bracing systems in modern buildings. The approximate process implemented by the ABNT NBR 6118:2003 [14] for sizing these elements has no similarity with what is presented by other standards that address this topic. The Brazilian situation is quite unique, however, especially concerning the loads that buildings will withstand throughout their working life, since very intense earthquakes are not to be found, at least in the more densely populated regions where there are the tallest buildings and more prone to suffer damages from horizontal loads. Therefore, we should really give a specific treatment to the shear walls in Brazilian buildings.

Although the approximate process implemented by ABNT NBR 6118:2003 [14] version has been widely criticized, it was kept in its 2014 version. The two key points that should be analyzed are the increase in the bending moment along the shear wall height, caused by the localized second order effects and the appearance of a bending moment along the length of the shear wall (largest dimension of the cross section).

Using this approximate process has resulted in a very high reinforcement rate (both longitudinal and transverse) in cases of shear walls with a rectangular section, and even in cases where the ratio between the largest and smallest size is close to the limit $(\mathrm{b}=5 \mathrm{~h})$.

A small sample will be presented here that could occur when sizing shear walls based on the recommendations of ABNT NBR 6118:2014 [1]. The data will be provided for eight buildings designed in the city of Teresina, Piauí State (PI). Table 2 
shows some of the main characteristics of these buildings, namely the number of floors, total height, tower blueprint dimensions, slenderness (ratio between total height and smallest dimension on plan) and the existence or otherwise of a rigid core.

Table 2. Characteristics of buildings

\begin{tabular}{|c|c|c|c|c|c|c|c|}
\hline \multirow{2}{*}{ Building } & \multirow{2}{*}{$\mathbf{N}^{0}$ Floors } & \multirow{2}{*}{ Height (m) } & \multicolumn{2}{|c|}{ Floor plan dimensions (m) } & \multicolumn{2}{|c|}{ Slenderness } & \multirow{2}{*}{ Rigid core } \\
\hline & & & $\mathbf{L x}$ & Ly & H/Lx & H/Ly & \\
\hline 1 & 24 & 74.9 & 20.43 & 22.08 & 3.67 & 3.39 & No \\
\hline 2 & 17 & 52.7 & 17.73 & 20.73 & 2.97 & 2.54 & No \\
\hline 3 & 22 & 64.4 & 41.21 & 19.68 & 1.56 & 3.27 & Yes \\
\hline 4 & 18 & 53.5 & 32.63 & 25.54 & 1.64 & 2.09 & Yes \\
\hline 5 & 18 & 55.0 & 29.20 & 30.90 & 1.88 & 1.78 & Yes \\
\hline 6 & 21 & 63.9 & 38.20 & 18.93 & 1.67 & 3.22 & Yes \\
\hline 7 & 11 & 32.2 & 25.54 & 17.39 & 1.26 & 1.85 & No \\
\hline 8 & 20 & 60.4 & 34.10 & 26.10 & 1.77 & 2.31 & Yes \\
\hline
\end{tabular}

This is a fairly heterogeneous sample since, as can be seen from the above table, the number of floors varies from 11 to 24 , total height from 32.2 to 74.9 meters and slenderness from 1.26 to 3.57 .

Table 3 shows the characteristics of some columns of these buildings. It illustrates that the ratio between the largest and smallest size of the cross section is always equal to 5, which is the limit value between a conventional column and shear wall. This did not occur by chance, and became a design guideline whenever possible to prevent the use of sections in which a ratio between their dimensions is more than 5. Otherwise, it would be necessary to increase the quantity of reinforcement to comply with ABNT NBR 6118:2014 [1], since it recommends that in such cases the localized effects are considered and that the quantity of transverse reinforcement must be $25 \%$ or more of the longitudinal reinforcement (except in cases where a horizontal bending study has been undertaken).

Table 3. Characteristics of columns

\begin{tabular}{|c|c|c|c|c|c|}
\hline \multirow{2}{*}{ Building } & \multirow{2}{*}{$\begin{array}{c}\text { Column } \mathbf{N}^{\mathbf{o}} \\
\mathbf{N}^{\mathbf{0}} \\
\end{array}$} & \multirow{2}{*}{$\frac{\text { Transversion section }}{\text { section }}$} & \multirow{2}{*}{$\begin{array}{c}\text { Longitudinal } \\
\text { reinforcement }\end{array}$} & \multicolumn{2}{|c|}{ Stirrup } \\
\hline & & & & Column & Shear wall \\
\hline \multirow{2}{*}{ Jacarandá } & $\mathrm{P} 11$ & $25 \times 125$ & $18 \varphi 25$ & $\Phi 8 \mathrm{c} / 20$ & $\Phi 8 \mathrm{c} / 5.7$ \\
\hline & $\mathrm{P} 15$ & $25 \times 125$ & $18 \varphi 25$ & $\Phi 8 \mathrm{c} / 20$ & $\Phi 8 \mathrm{c} / 5.7$ \\
\hline \multirow{4}{*}{ Jardim Fiesole } & $\mathrm{P} 2=\mathrm{P} 27$ & $25 \times 125$ & $12 \varphi 25$ & $\Phi 8 \mathrm{c} / 20$ & $\Phi 8 \mathrm{c} / 8.5$ \\
\hline & P5 & $20 \times 100$ & $8 \varphi 25$ & $\Phi 8 \mathrm{c} / 20$ & $\Phi 8 \mathrm{c} / 10$ \\
\hline & $\mathrm{P} 6=\mathrm{P} 7=\mathrm{P} 14$ & $25 \times 125$ & $16 \varphi 25$ & $\Phi 8 \mathrm{c} / 20$ & $\Phi 8 \mathrm{c} / 6.4$ \\
\hline & P18 & $30 \times 150$ & $28 \varphi 25$ & $\Phi 8 \mathrm{c} / 20$ & $\Phi 8 \mathrm{c} / 4.4$ \\
\hline \multirow{3}{*}{ Chamonix } & $\mathrm{P} 2=\mathrm{P} 4=\mathrm{P} 25$ & $30 \times 150$ & $26 \varphi 25$ & $\Phi 8 \mathrm{c} / 20$ & $\Phi 8 \mathrm{c} / 4.7$ \\
\hline & $\mathrm{P} 3=\mathrm{P} 26$ & $30 \times 150$ & $38 \varphi 25$ & $\Phi 8 \mathrm{c} / 20$ & $\Phi 8 \mathrm{c} / 3.2$ \\
\hline & P12 & $30 \times 150$ & $18 \varphi 25$ & $\Phi 8 \mathrm{c} / 20$ & $\Phi 8 \mathrm{c} / 6.8$ \\
\hline \multirow{4}{*}{ Jardim Positano } & $\mathrm{P} 3=\mathrm{P} 23$ & $30 \times 150$ & $32 \varphi 25$ & $\Phi 8 \mathrm{c} / 20$ & $\Phi 8 \mathrm{c} / 3.8$ \\
\hline & P6 & $25 \times 125$ & $16 \varphi 12.5$ & $\Phi 5 \mathrm{c} / 15$ & $\Phi 5 \mathrm{c} / 10$ \\
\hline & $\mathrm{P} 7=\mathrm{P} 22$ & $30 \times 150$ & $28 \varphi 25$ & $\Phi 8 \mathrm{c} / 20$ & $\Phi 8 \mathrm{c} / 3.8$ \\
\hline & P8 & $20 \times 100$ & $22 \varphi 16$ & $\Phi 5 \mathrm{c} / 19$ & $\Phi 5 \mathrm{c} / 3.6$ \\
\hline \multirow{3}{*}{ Savona Residence } & $\mathrm{P} 10=\mathrm{P} 13=$ & $30 \times 150$ & $18 \varphi 25$ & $\Phi 8 \mathrm{c} / 20$ & $\Phi 8$ c/6.8 \\
\hline & $\mathrm{P} 14=\mathrm{P} 18$ & $30 \times 150$ & $10 \% 2 J$ & प० प 20 & $\Phi 0 \mathrm{c} / 0.0$ \\
\hline & $\mathrm{P} 44=\mathrm{P} 68$ & $25 \times 125$ & $16 \varphi 25$ & $\Phi 8 \mathrm{c} / 20$ & $\Phi 8 \mathrm{c} / 6.4$ \\
\hline \multirow{6}{*}{ Maranhata } & $\mathrm{P} 9=\mathrm{P} 27$ & $25 \times 125$ & $20 \varphi 25$ & $\Phi 8 \mathrm{c} / 20$ & $\Phi 8 \mathrm{c} / 5.1$ \\
\hline & P13 & $30 \times 150$ & 18 & $\Phi 8 \mathrm{c} / 20$ & $\Phi 8 \mathrm{c} / 3.4$ \\
\hline & P16 & $25 \times 125$ & $20 \varphi 25$ & $\Phi 8 \mathrm{c} / 20$ & $\Phi 8 \mathrm{c} / 5.6$ \\
\hline & P17 & $25 \times 125$ & $26 \varphi 25$ & $\Phi 8 \mathrm{c} / 20$ & $\Phi 8 \mathrm{c} / 4.7$ \\
\hline & $\mathrm{P} 20=\mathrm{P} 23$ & $25 \times 125$ & $24 \varphi 25$ & $\Phi 8 \mathrm{c} / 20$ & $\Phi 8 \mathrm{c} / 4.3$ \\
\hline & $\mathrm{P} 22$ & $25 \times 125$ & $16 \varphi 25$ & $\Phi 8 \mathrm{c} / 20$ & $\Phi 8 \mathrm{c} / 6.4$ \\
\hline
\end{tabular}

Table 3 also shows the longitudinal and transverse reinforcements obtained for sizing, considering a conventional column, in addition to the quantity of transverse reinforcement necessary to comply with ABNT NBR 6118:2014 [1] 
should the column be considered a shear wall and the relationship between these quantities as transverse reinforcement. This increase in transverse reinforcement was fairly high, varying from 2 to 6.2 times the necessary value for a conventional column, and without taking into account the localized effect that would probably result in an increase in longitudinal reinforcement and, consequently, in an even greater quantity of transverse reinforcement. This increase in reinforcement could result not only in a higher cost of the column but also its unfeasible implementation.

\section{NUMERICAL SIMULATIONS}

The first steps in performing a numerical simulation are to define the models to be used and to select the computer program. The main computer models used for numerical simulation of shear walls are three-dimensional models (solid elements), two-dimensional (plane stresses, plane deformations, shells), macro models and bar element models. In this study three-dimensional models were used as well as bar element models with a single bar (vertical) and bar element models consisting of a bar mesh (vertical and horizontal).

Two commercial computer programs were used, - MIDAS-FEA for numerical simulations with three-dimensional elements, and CAD-TQS for bar element models. It should be mentioned that it was only possible to use CAD-TQS by implementing some specific routines for this study, which are not available in the commercial version of the program. These routines were implemented by the courtesy of the TQS company technical team.

\subsection{Single bar model}

The models that use a single bar to represent a stretch of a column were used not only to simulate the entire section of the shear wall as if it were a single bar, but also to simulate isolated strips of shear walls obtained by using the approximate process in ABNT NBR 6118:2014 [1], each strip represented by an isolated bar. In this model each node has six degrees of freedom.

The geometric and physical nonlinearity were considered in models that use bar elements. The General Method was used in which the geometric nonlinearity was taken into account using the interactive P- $\delta$ process, through the load increment method. The total load was divided into 20 equal increments. The bars were divided into 12 equal parts and a finite element model was used to obtain the results. The physical nonlinearity was considered using the diagram $\mathrm{M}$, $\mathrm{N}, 1 / \mathrm{r}$, as described by Ribeiro [15].

The consideration of the physical nonlinearity was a point where it was necessary to request an adjustment to the mesh model available in CAD-TQS, since the drying rigidity obtained for the section by linearizing the diagram $M, N$, $1 / r$ uses the design maximum moment value withstood by the section $\left(M_{R d}\right)$ and not the value of the design stress moment on the section $\left(M_{S d}\right)$. This is the procedure recommended by ABNT NBR 6118:2014 and can be adopted in designs, with no problem whatsoever, since it is conservative, but when using this procedure it may cause inconsistency in the results. This inconsistency was found in this study, which is why it was necessary to be adjusted in the CADTQS model.

\subsection{Mesh model}

This model consists of a mesh of horizontal and vertical bars. In it each vertical bar represents a strip of the shear wall obtained using the approximate process of ABNT NBR 6118:2014 [1]. Each vertical bar was divided into ten elements and their nodes were linked to the nodes of the adjacent strip by horizontal bars, to prevent a strip from being deformed independently of the others. As a result a point is eliminated, in which the approximate process of ABNT NBR 6118:2014 is widely criticized, perhaps the point most severely criticized of all.

In this model the geometric and physical linearity of the vertical bars are considered in the same way as in the single bar model and horizontal bars are considered elastic and linear with the characteristics of the gross concrete section, according to TQS [16].

\subsection{Three-dimensional models}

Three-dimensional models were made using the computer program MIDAS-FEA, in which the concrete was modeled using hexahedral solid elements, with eight nodes, and steel bars were modeled using the Line 3D element, in which the bar axis is defined and the program automatically converts the line into a solid element. To avoid problems when introducing loading, rigid blocks were created at the top and bottom of the columns and also modeled using hexahedral solid elements according to MIDAS [17]. 
The material used to represent the behavior of the concrete was Total Strain Crack, which describes the tensile and compressive behavior of a material with one stress-strain relationship. When the concrete undergoes tensile deformations the constituent ratio was defined using the Brittle function, which is a bilinear function whose diagram is represented in Figure 4a, where $\mathrm{f}_{\mathrm{t}}$ is the concrete's tensile strength. In case of compressive deformation the constituent ratio was defined by the function of Thorenfeldt, which is a non-linear function whose diagram is represented in Figure $4 \mathrm{~b}$, where $\mathrm{f}_{\mathrm{c}}$ is the concrete's compressive strength.

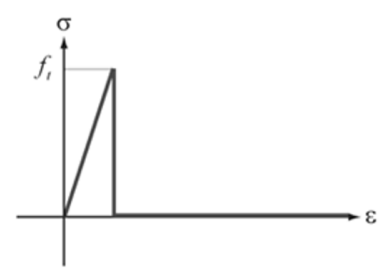

(a) Tensile

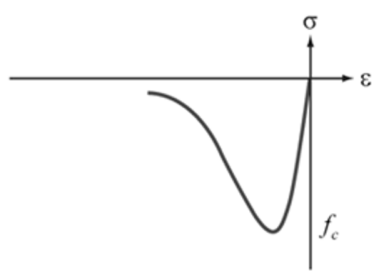

(b) Compression

Figure 4. Stress-strain diagrams of concrete

The von Mises model was used to represent the behavior of the steel and rigid block, in which it is necessary to specify the elastic modulus, Poisson's ratio and the tensile elastic modulus, according to MIDAS [17].

\subsection{Validation of computer models}

To validate the computer models, results were used from the experimental work undertaken by Melo [18]. This study involved the experimental analysis of 24 reinforced concrete columns undergoing normal flexure and axial compression in the Structures Laboratory of the University of Brasília. The experimental program consists of three test series, with ten columns in Series 1, seven in Series 2 and seven in Series 3. The columns were identified as follows: PFN e-L, where:

PFN -column under flexure and axial compression normal stresses;

$\mathrm{e}$ - value of eccentricity toward least inertia, in millimeters;

$\mathrm{L}$-length of column in meters.

Table 4 shows the characteristics of the tested columns. It is worth mentioning that the columns undergoing centered compression have the same name.

To validate the computer models, numerical simulations were made only in the cases where the section was actually submitted to the normal unsymmetrical bending, with a total of 21 cases since three cases were under centered compression (PFN 0-3, PFN 0-2.5 and PFN 0-2). In these simulations the three-dimensional models and single bar models were used without considering transverse reinforcements.

Figure 6 illustrates the three-dimensional model of case $P F N$ 24-2. It provides an overview of the finite element mesh (a), the lines representing the steel bars (b) and a detail of the rigid block when being loaded (c). The model consists of two rigid blocks with the same dimensions of $12 \mathrm{~cm} \mathrm{x} 25 \mathrm{~cm} \mathrm{x} 12 \mathrm{~cm}(\mathrm{x}, \mathrm{y}, \mathrm{z})$, one on top and another at the bottom, in addition to the middle stretch with dimensions equal to $12 \mathrm{~cm} \mathrm{x} 25 \mathrm{~cm} \mathrm{x} 176 \mathrm{~cm}$ (x,y,z).

The program automatically created a mesh, taking as reference a $4 \mathrm{~cm}$ dimension for the elements. Thus each rigid block consists of 128 elements and the central part comprises 1888 elements.

Loading was introduced by applying the concentrated loads to the nodes of the two rigid blocks (top and bottom). The vertical load was applied to the nodes along the axis towards $x$ that is in the middle of the cross section and the moment was applied using a binary along the axes towards $x$ that are on the edges of the cross section. In order for the concentrated loads to be standardized in a small stretch and for the deformations of these elements to be very small, a linear elastic material was used in the rigid blocks with a high elastic modulus value equal to $100,000 \mathrm{GPa}$.

The boundary conditions were introduced by applying restraints to the nodes of the rigid blocks. The boundary conditions represent an articulated column; to do so, restraints were imposed on the nodes placed along the axis towards $x$ in the middle of the cross section. Shifts were prevented towards axes $x$ and $y$, leaving the rotations free around the three axes $(x, y, z)$ and the shift towards axis $z$. 
The characteristics of the materials representing the concrete and steel were obtained from test samples performed by Melo [18]. In the PFN 24-2 case, the concrete strength was equal to $38.5 \mathrm{MPa}$, the elastic modulus of the concrete was $20.6 \mathrm{GPa}$, the yield stress of steel was $595 \mathrm{MPa}$ and the elastic modulus of the steel was $190 \mathrm{GPa}$. The slenderness ratio is 52.2 and a normal force is applied with relative eccentricity $(e / h)$ of 0.20 .

Table 4. Characteristics of tested columns [18]

\begin{tabular}{|c|c|c|c|c|c|c|c|c|}
\hline Series & Column & e (mm) & e/h & $\lambda$ & L (cm) & $\operatorname{Ac}\left(\mathrm{cm}^{2}\right)$ & As $\left(\mathrm{cm}^{2}\right)$ & $\rho(\%)$ \\
\hline \multirow{10}{*}{1} & PFN 0-3 & 2 & 0.00 & \multirow{10}{*}{92.7} & \multirow{10}{*}{300} & \multirow{10}{*}{300} & \multirow{10}{*}{4.71} & \multirow{10}{*}{1.57} \\
\hline & PFN 6-3 & 6 & 0.05 & & & & & \\
\hline & PFN 12-3 & 12 & 0.10 & & & & & \\
\hline & PFN 15-3 & 15 & 0.13 & & & & & \\
\hline & PFN 18-3 & 18 & 0.15 & & & & & \\
\hline & PFN 24-3 & 24 & 0.20 & & & & & \\
\hline & PFN 30-3 & 30 & 0.25 & & & & & \\
\hline & PFN 40-3 & 40 & 0.33 & & & & & \\
\hline & PFN 50-3 & 50 & 0.42 & & & & & \\
\hline & PFN 60-3 & 60 & 0.50 & & & & & \\
\hline \multirow{7}{*}{2} & PFN 0-2.5 & 0 & 0.00 & & & & & \\
\hline & PFN 15-2.5 & 15 & 0.13 & & & & & \\
\hline & PFN 24-2.5 & 24 & 0.20 & & & & & \\
\hline & PFN 30-2.5 & 30 & 0.25 & 71.5 & 250 & 300 & 4.71 & 1.57 \\
\hline & PFN 40-2.5 & 40 & 0.33 & & & & & \\
\hline & PFN 50-2.5 & 50 & 0.42 & & & & & \\
\hline & PFN 60-2.5 & 60 & 0.50 & & & & & \\
\hline \multirow{7}{*}{3} & PFN 0-2 & 0 & 0.00 & & & & & \\
\hline & PFN 15-2 & 15 & 0.13 & & & & & \\
\hline & PFN 24-2 & 24 & 0.20 & & & & & \\
\hline & PFN 30-2 & 30 & 0.25 & 52.2 & 200 & 300 & 4.71 & 1.57 \\
\hline & PFN 40-2 & 40 & 0.33 & & & & & \\
\hline & PFN 50-2 & 50 & 0.42 & & & & & \\
\hline & PFN 60-2 & 60 & 0.50 & & & & & \\
\hline
\end{tabular}

All these columns have a cross section $12 \mathrm{~cm}$ x $25 \mathrm{~cm}$, longitudinal reinforcement consisting of six CA-50 steel bars $10 \mathrm{~mm}$ in diameter and transverse reinforcement consisting of CA-60 steel stirrups $5 \mathrm{~mm}$ in diameter and $10 \mathrm{~cm}$ spacing between them, see Figure 5 .

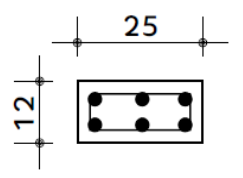

Figure 5. Cross section of columns

To validate the numerical models a comparison was made between the values of the maximum horizontal displacements. In the numerical models the failure load value (obtained in tests) was divided into 20 load increments and a nonlinear analysis was made with a maximum number of interactions equal to 100. Figure 7 shows the deformation of column PFN 24-2 at the moment of collapse and the displacements towards $x$ obtained by numerical simulations for the three-dimensional and bar element models. 


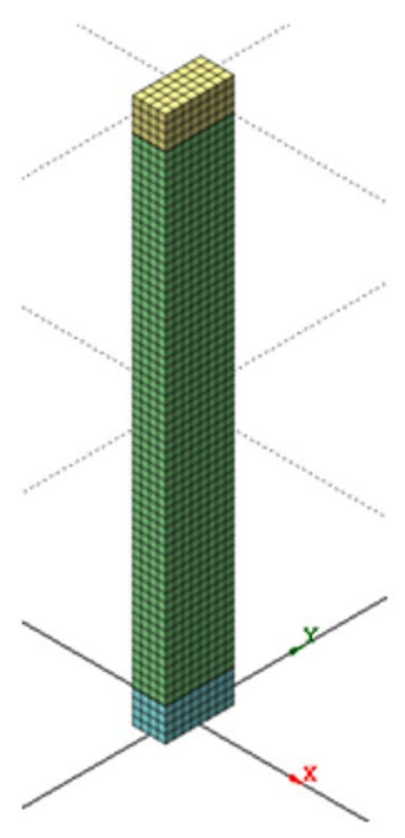

(a)

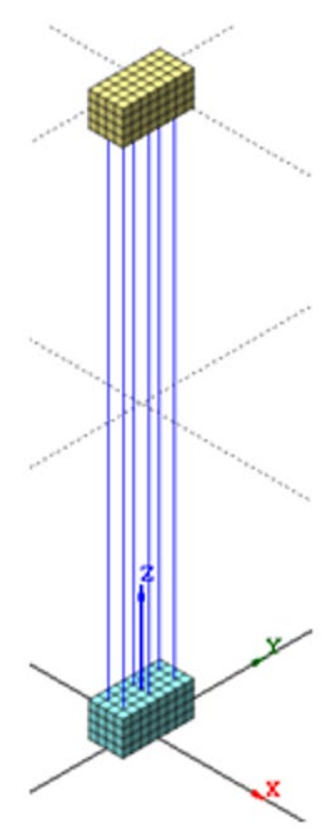

(b)

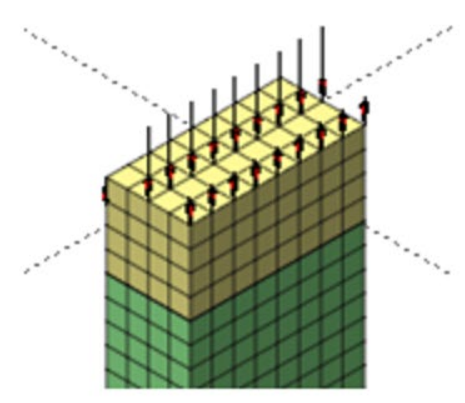

(c)

Figure 6. Three-dimensional model in the $P F N 24-2$ case
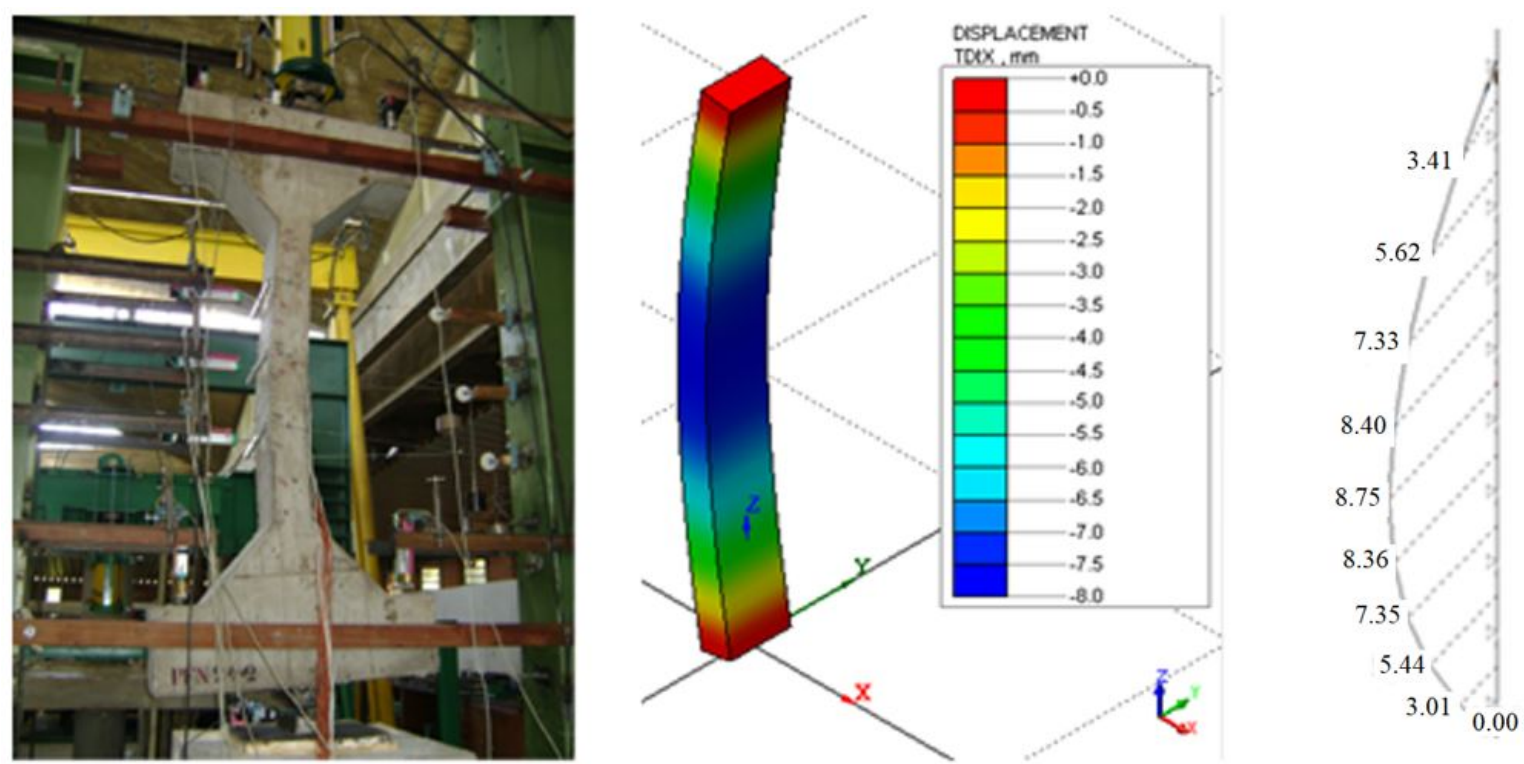

Figure 7. Displacements in column PFN 24-2

Figure 8 provides a diagram with the comparison of the results of the vertical load-horizontal displacement ratio obtained in the experimental analysis, numerical analysis with three-dimensional (3D) elements and numerical analysis with bar elements in the case of column PFN 24-2. This figure shows a good match between results. The resulting values for the horizontal displacements as the value of the force increases are practically the same for the three models until a vertical load value of $300 \mathrm{kN}$. From this point on the displacements in the $3 \mathrm{D}$ model are slightly smaller than in the other two models. There is a very good match between the bar model and the experimental model up to the conventional failure load of the bar model, which is determined by limiting the deformations in steel and concrete, $10 \%$ 
e $3.5 \%$, respectively. As the experimental model does not have this limitation, it reaches higher values for the breaking load and the corresponding displacement. The failure load values, and their displacements were: $440 \mathrm{kN}$ and $14 \mathrm{~mm}$ for the experimental analysis; $456 \mathrm{kN}$ and $8 \mathrm{~mm}$ for the 3D model; $410 \mathrm{kN}$ and $9 \mathrm{~mm}$ for the bar model.

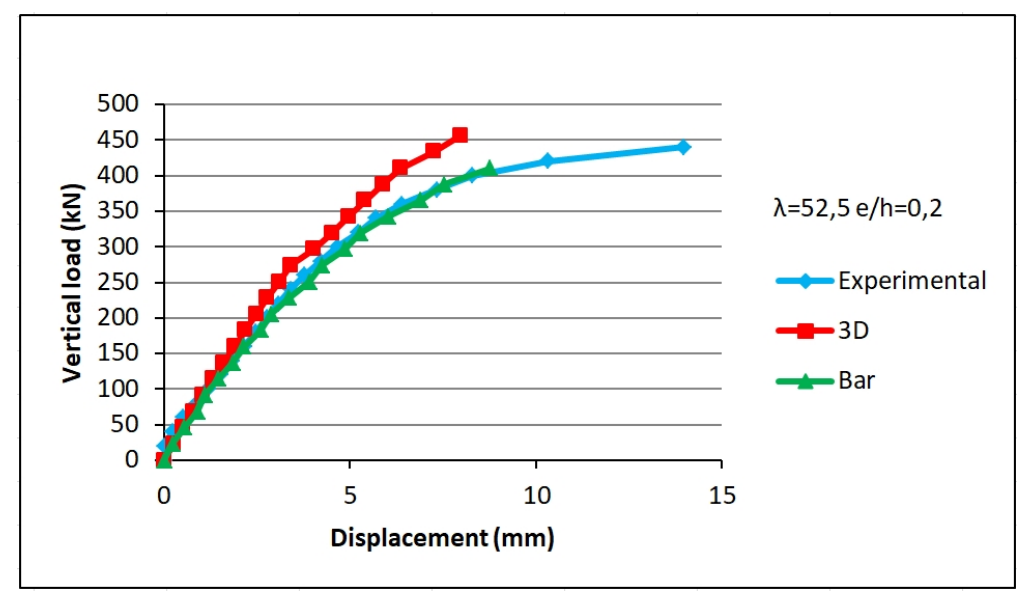

Figure 8. Diagram maximum load displacement - $P F N$ 24-2

\subsection{Definition of the analyzed cases}

The definition of the analyzed cases was based on the main variables that might influence the behavior of the shear walls: a ratio between the cross section dimensions $(b / h)$; value of the slenderness index $(\lambda)$; value of the calculated dimensionless normal strain $\left(v_{d}\right)$; and the value of the calculated dimensionless bending moment around the axis of greatest inertia of the cross section $\left(\mu_{b d}\right)$.

Cross sections were studied with the following value of the ratio between the cross section dimensions: $b / h=5$; $b / h=7.5 ; b / h=10 ; e b / h=15$. For each $b / h$ value six different numerical models were made, with the slenderness ratio varying between the limits specified by ABNT NBR 6118:2014 [1] for using the simplified process: $\lambda=36 ; \lambda=50 ; \lambda=60$; $\lambda=70 ; \lambda=80$; and $\lambda=90$. Thus, a total of 24 computer models were obtained.

Each model was processed for six different values of design dimensionless normal force, within limits normally used in preparing designs: $v_{d}=0.1 ; v_{d}=0.3 ; v_{d}=0.5 ; v_{d}=0.7 ; v_{d}=0.9 ; v_{d}=1.1$. Ten different values of $\mu_{b d}$ were applied for each value of $v_{d}$.

The maximum value of the dimensionless bending moment applied to the section was determined by the rise of tensile strains caused by it. This value was obtained by multiplying the normal force value by an approximately $1 / 5$ equal relative eccentricity $(e / b)$, which is slightly higher than the relative eccentricity that defines the center core of inertia of a rectangular section. Therefore, although tensile strains appear on the outside surface of the cross section, they are low in intensity so that in every case analyzed the bar representing the strip at the end pulled by the bending moment remained with a normal compressive force. This maximum value of a dimensionless bending moment was divided into ten moment portions, totaling 1,440 analyzed cases.

Each of these cases was analyzed by three different bar models. In the first model the shear wall is analyzed as if it were a conventional column, being represented by a single vertical bar. In the second model the shear wall is analyzed according to the simplified model of ABNT NBR 6118:2014 [1]; that is, it is represented by a model consisting of separate vertical bars, in which each bar represents a strip of the shear wall. In the third model the shear wall is analyzed using the mesh model, in which horizontal bars connect the vertical bars representing the strips.

In every case design dimensionless bending moments were applied around the axis of the smallest inertia of the cross section $\left(\mu_{h d}\right)$ equal to the minimum moments specified by ABNT NBR 6118:2014 [1].

The geometry definitions of models, concrete strengths and covers of the reinforcements took into consideration the recommendations of ABNT NBR 6118:2014 [1]. With a view to using values coherent with design practice and that were somewhat conservative, the lowest value permitted by ABNT NBR 6118:2014 [1] was adopted for the smallest dimension of the shear walls, namely, $h=14 \mathrm{~cm}$. The characteristic strength adopted for the concrete was $25 \mathrm{MPa}$, which is the lowest value recommended by ABNT NBR 6118:2014 [1] for uncovered concrete structures in urban zones. The value of $3 \mathrm{~cm}$ was considered for covering reinforcements (c). 
For these $h$ and $c$ values there is a relatively low efficient reinforcement, since the distance from the latter to the center of gravity of the section is small, confirming the conservative nature of this situation. However, the adopted value may be questioned for the covering of the reinforcements, since if the structure is located in a region where the environment is more aggressive, it would necessarily have a higher cover that would result in an even lower efficiency of the reinforcement. Yet in such situations $h$ values equal to the minimum are seldom adopted.

With the definition of the $h$ value, the $b$ values were automatically defined as a result of the $b / h$ ratio, as were the values of the buckling lengths as a result of the $\lambda$ values. Having defined the sizes of the cross sections and concrete strength, the load forces were also automatically defined as a result of the dimensionless values of the normal force and bending moment.

Table 5 shows the characteristics of some of the models that were analyzed. The values of slenderness were 36,50 , $60,70,80$ e 90 (this is the limit permitted for the use of the simplified process of ABNT NBR 6118:2014 [1]).

Table 5. Characteristics of models $P P 1$ to $P P 6(b=0.71 m ; h=0.14 m ; b / h=5)$

\begin{tabular}{|c|c|c|c|c|c|c|c|c|c|c|c|c|}
\hline & \multirow{2}{*}{$v_{d}$} & \multirow{2}{*}{$\mu_{\mathrm{hd}}$} & \multicolumn{10}{|c|}{$\mu_{\mathrm{bd}}$} \\
\hline & & & 1 & 2 & 3 & 4 & 5 & 6 & 7 & 8 & 9 & 10 \\
\hline PP1 & 0.10 & 0.01 & 0.002 & 0.004 & 0.006 & 0.008 & 0.010 & 0.012 & 0.015 & 0.017 & 0.019 & 0.021 \\
\hline PP2 & 0.30 & 0.04 & 0.006 & 0.012 & 0.019 & 0.025 & 0.031 & 0.037 & 0.044 & 0.050 & 0.056 & 0.062 \\
\hline PP3 & 0.50 & 0.07 & 0.011 & 0.021 & 0.032 & 0.042 & 0.053 & 0.063 & 0.074 & 0.084 & 0.095 & 0.105 \\
\hline PP4 & 0.70 & 0.10 & 0.015 & 0.029 & 0.044 & 0.059 & 0.074 & 0.088 & 0.103 & 0.118 & 0.133 & 0.147 \\
\hline PP5 & 0.90 & 0.12 & 0.019 & 0.038 & 0.057 & 0.076 & 0.095 & 0.114 & 0.133 & 0.151 & 0.170 & 0.189 \\
\hline PP6 & 1.10 & 0.15 & 0.023 & 0.047 & 0.070 & 0.093 & 0.117 & 0.140 & 0.163 & 0.187 & 0.210 & 0.233 \\
\hline
\end{tabular}

The methodology adopted to perform the numerical simulations was as follows: for each case, the first step was to determine the reinforcement, dimensioning the shear walls if it were a conventional column, taking into account only the local second order effects, that is without considering the localized second order effects. The second step analyzes the shear wall using the approximate process of ABNT NBR 6118:2014 [1], and in the third step, the shear wall was analyzed using the mesh model.

In every case the reinforcements determined in the first step were used, even though they were not enough to withstand the forces determined by the models in the second and third steps. Therefore, the localized second order effects for both the isolated bar model and the mesh model are always determined conservatively.

The type of steel used was CA-50 and the reinforcement rates adopted complied with the limits specified by ABNT NBR 6118:2014 [1]. The values of the reinforcement rates varied from a minimum value of $0.4 \%$ to a maximum of $8 \%$.

\section{RESULTS AND DISCUSSIONS}

When analyzing the second order effects a comparison was made of the values of all moments (first order + second order) in the longest outside strip of the shear walls. The values obtained by the single bar model (conventional column) were compared to the values obtained by the isolated bar model, according to the approximate process of ABNT NBR 6118:2014 [1], and with the values obtained by the mesh model. To do so, the values for the single bar model were divided by the number of vertical bars of the other models.

In the simulations using the isolated bar model it was found in a number of cases that the end parts showed very different displacements from the displacements in the adjacent strip, a fact that it is impossible to occur in actual shear walls and that evidences the shortcoming of the simplified process. This behavior was observed in both the end strips compressed by the bending moment and the strips pulled by it. When using the mesh model, this defect is solved, as can be seen in Figures 9 and 10. In these figures the bars of the left end are compressed by the bending moment while the bars on the right end are pulled.

Figure 9 illustrates that for the independent bar model the maximum displacement of the longest bar is $53 \mathrm{~mm}$, more than twice as long as the value of the adjacent bar, which is $26 \mathrm{~mm}$ and more than three times longer than the value of the bar at the opposite end which is $17 \mathrm{~mm}$. In the mesh model case, the maximum displacement values are the same for all bars, equal to $23 \mathrm{~mm}$. 


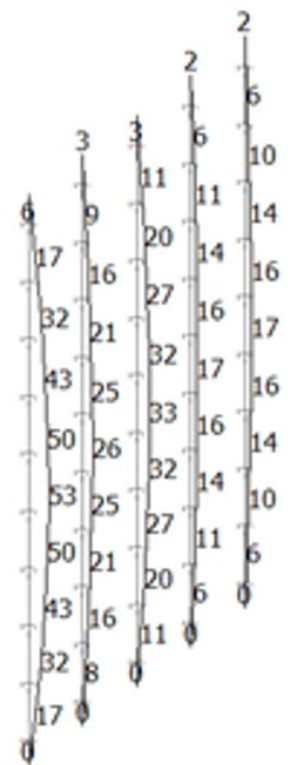

(a)

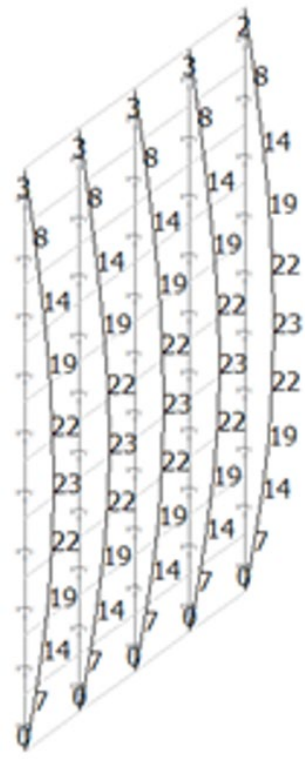

(b)

Figure 9. Displacement (mm) - CasePP21 ( $\left.\lambda=90 ; \mu_{b d}=0.029\right)$ - (a) Independent bars; (b) Mesh

Figure 10 shows that for the model of independent bars, the maximum displacement of the end pulled by the bending moment is $11 \mathrm{~mm}$, more than five times more in value than that of the other bars, which are equal to $2 \mathrm{~mm}$. In the mesh model case, every bar has the maximum displacement of $2 \mathrm{~mm}$.

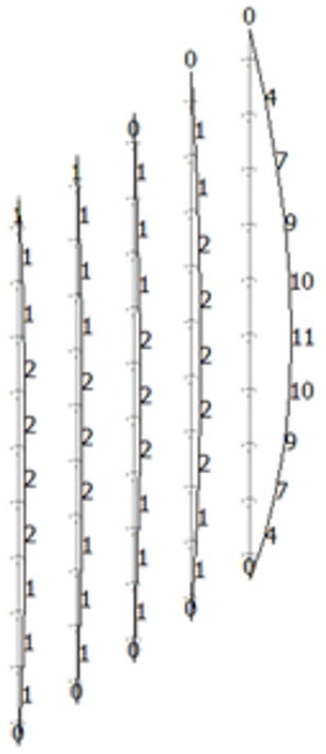

(a) Independent bars

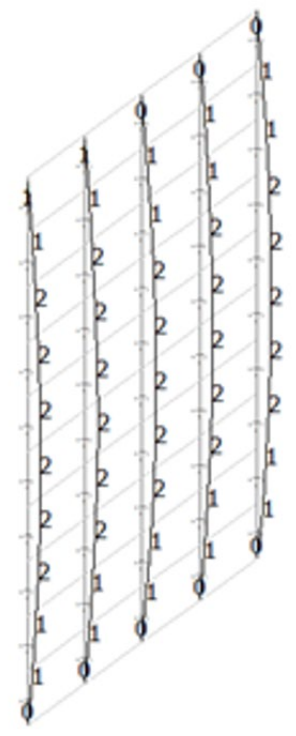

(b) Mesh

Figure 10. Displacement (mm) - Case PP19 $\left(\lambda=80 ; \mu_{b d}=0.020\right)$ 
In order to prove the results obtained by the mesh model, analyses were also made using three-dimensional models for these two cases. The results are shown in Figure 11.
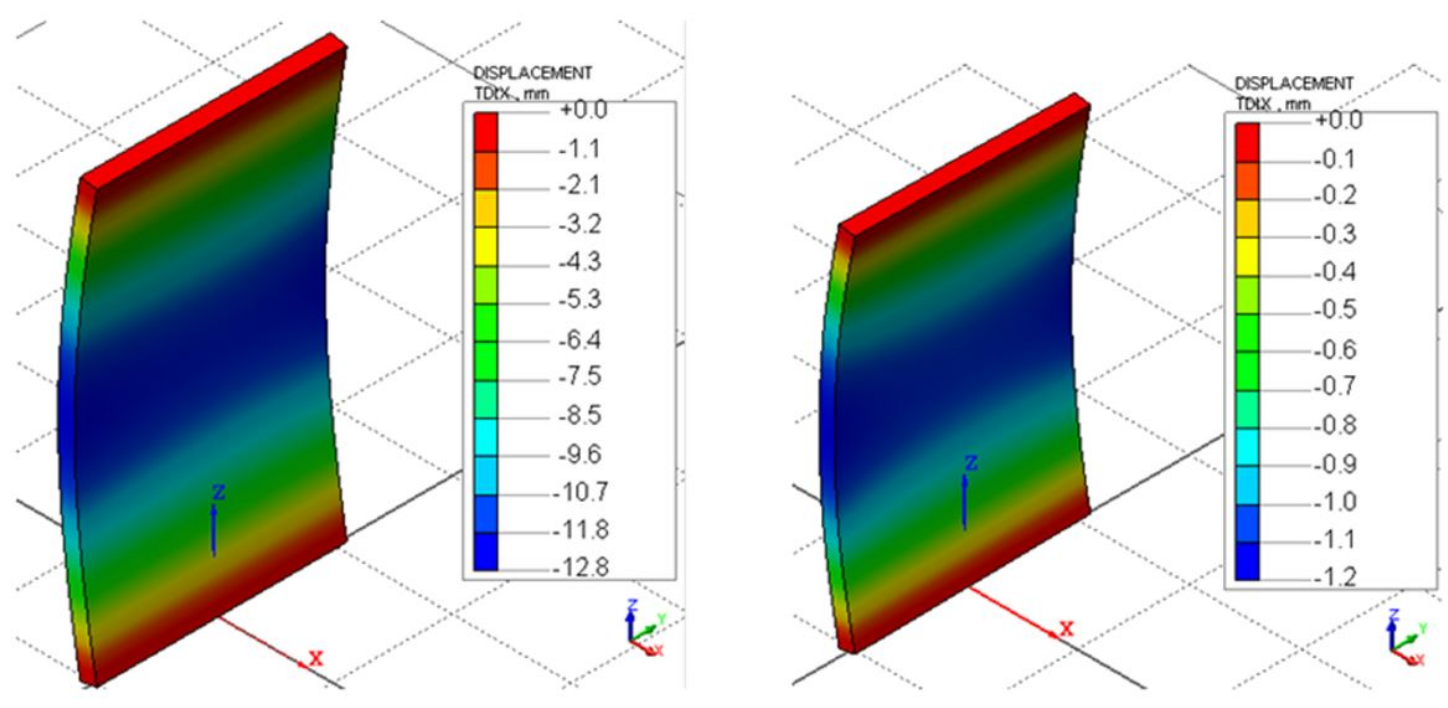

Figure 11. Displacement (mm) - 3D model

In the same way as in the mesh models, in the three-dimensional models the maximum displacement values are practically the same throughout the cross section. In case PP21 $\left(\lambda=90 ; \mu_{b d}=0.029\right)$ the result for the node situated in the axis of the cross section of the end compressed by the bending moment was $12.79 \mathrm{~mm}$ and the result for the node situated in the axis of the cross section of the end pulled by the bending moment was $12.81 \mathrm{~mm}$. In case $P P 19(\lambda=80$; $\left.\mu_{b d}=0.020\right)$ the result for the node situated in the axis of the cross section at the end compressed by the bending moment was $1.19 \mathrm{~mm}$, and the result for the node situated in the axis of the cross section at the end pulled by the ending moment was $1.17 \mathrm{~mm}$.

\subsection{Bending moment in the vertical direction}

To analyze the influence of the localized second order effects on the total bending moment value in the vertical direction of the shear walls, a comparison was made of the results obtained in three different ways. When the shear wall is analyzed by a single bar (as if it were a conventional column) there are no localized second order effects. When comparing the results of this model with the results from the isolated bar and mesh models it was possible to determine the influence of the localized second order effects. In other words, the differences in the values of the bending moments obtained from these last two models in relation to the values obtained from the first model come from the localized second order effects.

The results are presented in graphs showing the variation in the maximum bending moment in the bar with the longest end as a result of the main variables that can interfere in the results, as follows: the ratio between the dimensions of the cross section $(b / h)$; slenderness $(\lambda)$; the design dimensionless normal force $\left(v_{d}\right)$; and design dimensionless bending moment around the axis with the highest inertia of the cross section $\left(\mu_{b d}\right)$.

It is obvious that in case $P P 1$, shown in Figure 12, when there is little slenderness the bending moment values are only slightly altered as the $\mu_{b d}$ value increases, and that the bending moment values are practically the same for the three models. When the slenderness value increases, the bending moment values now increase as the $\mu_{b d}$ value increases, and the values determined by the three models now no longer coincide. The values of the isolated bar and mesh models (NBR) are higher than the values from the single bar model (column), indicating the existence of the localized second order effects. 


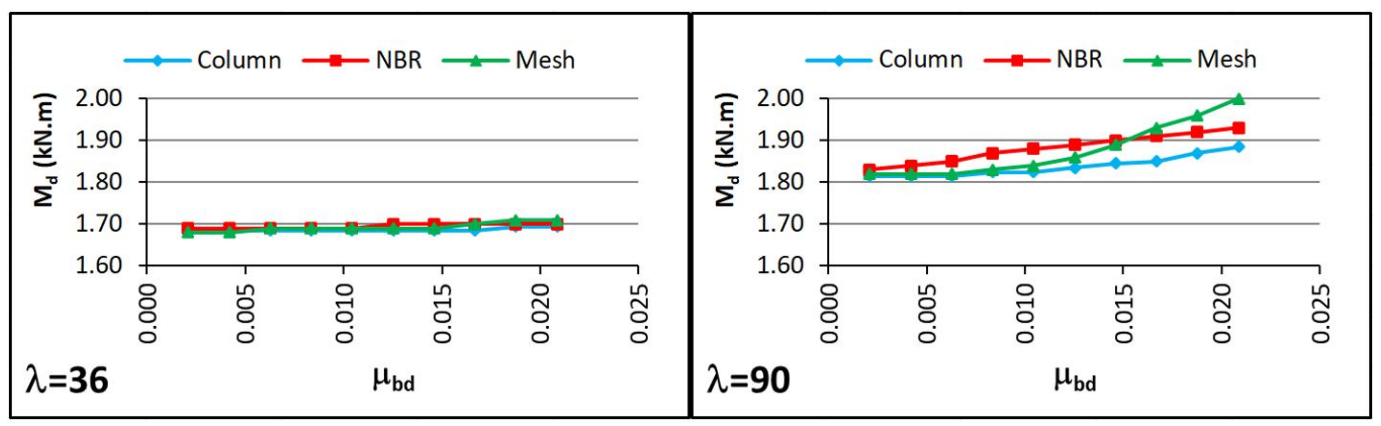

Figure 12. Diagrams $M_{d} x \mu_{b d}$ for the case $P P 1\left(b / h=5 ; v_{d}=0.1\right)$

In order to quantify the localized second order effects, diagrams were built relating the values of the bending moments obtained from the single bar model with the values from the other two models, in which the vertical axes are the values of the bending moments obtained from the isolated bar and mesh models, divided by the values obtained from the single bar model $\left(M_{d} / M_{d, C O L U M N}\right)$.

It is possible when analyzing the diagrams in Figure 13 to confirm that when the slenderness is small the values from the three models are practically the same since the ratios between them are very close to 1.0 . For higher slenderness values, as the value of $\mu_{b d}$ increases the ratio $M_{d} / M_{d, C O L U M N}$ also increases, reaching a maximum value of 1.03 for the isolated bar model and 1.06 for the mesh model.

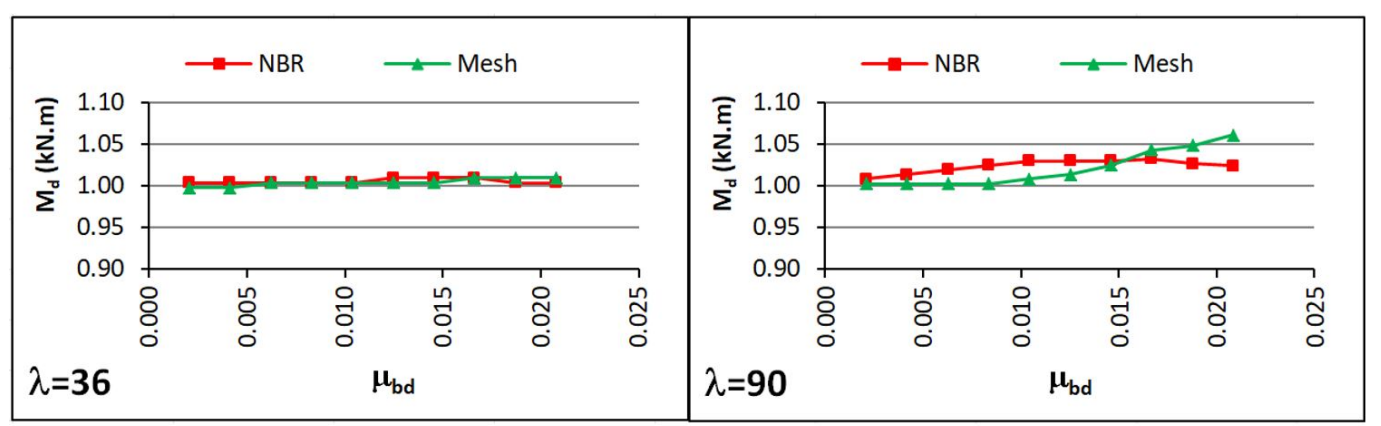

Figure 13. Diagrams $M_{d} / M_{d, C O L U M N} x \mu_{b d}$ for the case $P P 1\left(b / h=5 ; v_{d}=0.1\right)$

To analyze the influence of the ratio $b / h$ on the localized second order effects, the diagrams in Figure 14 were prepared. In those diagrams the vertical axis represents the ratio $M_{d, M E S H} / M_{d, C O L U M N}$ and the horizontal axis represents the $\mu_{b d}$ values.

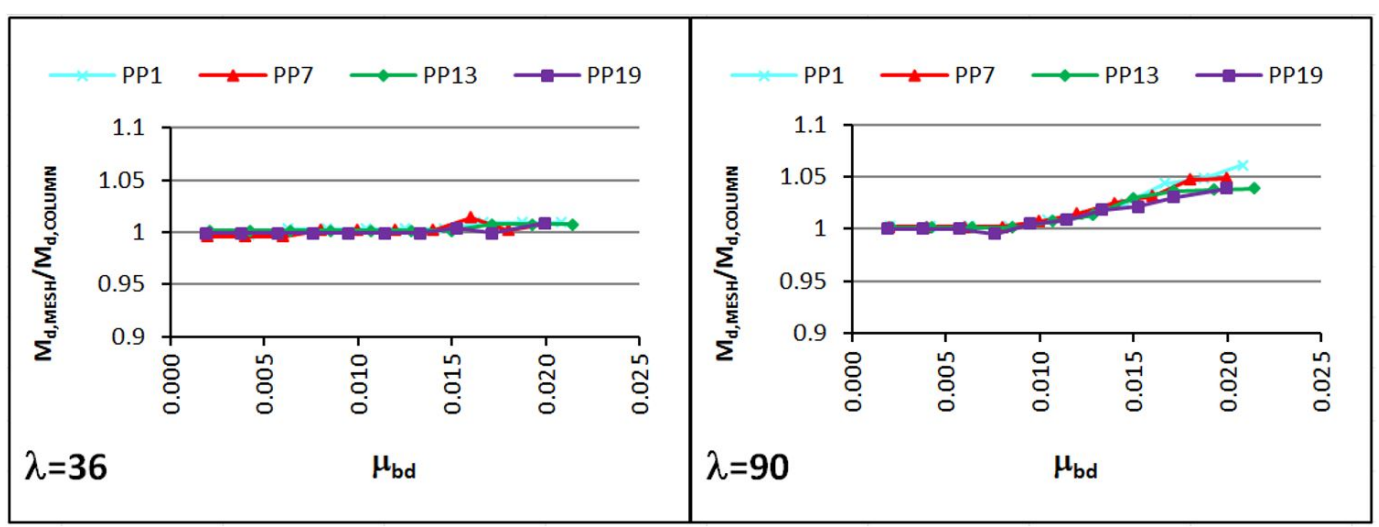

Figure 14. Diagrams $M_{d, M E S H} / M_{d, C O L U M N} x \mu_{b d}$ in cases where $v_{d}=0.1$ 
Figure 14 shows the results for cases $P P 1 \quad(b / h=5), P P 7(b / h=7.5), P P 13(b / h=10)$ and $P P 19(b / h=15)$, in which the value of the dimensionless normal force is 0.1 . It is clear in this figure that in the cases of little slenderness the values of the ratios $M_{d, M E S H} / M_{d, C O L U M N}$ are very close to 1.0 , for any values of $\mu_{b d}$. For more slenderness, as the value of $\mu_{b d}$ increases, the values of the ratios $M_{d, M E S H} / M_{d, \text { COLUMN }}$ also increase to reach a maximum value of 1.07.

Diagrams similar to those shown in Figures 12, 13 and 14 were made for all 1,440 cases analyzed with values of $\lambda=36, \lambda=50, \lambda=60, \lambda=70, \lambda=80$ and $\lambda=90$. Table 6 summarizes the maximum values obtained for the ratio $M_{d, M E S H} / M_{d, \text { COLUMN }}$. Almost all cases have a low value for this ratio, except where $v_{d}=0.3$ that reaches a maximum value of 1.21 .

Table 6. Summary of $M_{d, M E S H} / M_{d, C O L U M N}$ values

\begin{tabular}{ccccccc}
\hline & \multicolumn{5}{c}{$\mathbf{M}_{\mathbf{d M E S H}} / \mathbf{M}_{\mathbf{d} \text {.COLUMN }}$} & \multirow{2}{*}{ Maximum } \\
\cline { 2 - 5 } $\mathbf{v}_{\mathbf{d}}$ & $\mathbf{5}$ & $\mathbf{7 . 5}$ & $\mathbf{1 0}$ & $\mathbf{1 5}$ & 1.06 \\
\hline 0.10 & 1.06 & 1.05 & 1.04 & 1.04 & 1.21 \\
\hline 0.30 & 1.21 & 1.16 & 1.13 & 1.13 & 1.13 \\
\hline 0.50 & 1.08 & 1.10 & 1.09 & 1.13 & 1.08 \\
\hline 0.70 & 1.04 & 1.06 & 1.08 & 1.07 & 1.07 \\
\hline 0.90 & 1.04 & 1.03 & 1.03 & 1.07 & 1.05 \\
\hline 1.10 & 1.01 & - & 1.01 & 1.05 & \\
\hline
\end{tabular}

Table 7 summarizes the maximum values obtained for the ratio $M_{d, B A R} / M_{d, C O L U M N}$. High values for this ratio are to be found, reaching a maximum of 1.89. By comparing the vales in those two tables, it is evident that the isolated bar model always presents higher values than the mesh model, in some cases with a significant difference.

Table 7. Summary of $M_{d, B A R} / M_{d, C O L U M N}$ values

\begin{tabular}{|c|c|c|c|c|c|}
\hline \multicolumn{6}{|c|}{$\mathbf{M}_{\mathrm{dBAR}} / \mathbf{M}_{\mathrm{dCOLUMN}}$} \\
\hline \multirow{2}{*}{$v_{d}$} & \multicolumn{4}{|c|}{$\mathbf{b} / \mathbf{h}$} & \multirow{2}{*}{ Maximum } \\
\hline & 5 & 7.5 & 10 & 15 & \\
\hline 0.10 & 1.03 & 1.05 & 1.06 & 1.07 & 1.07 \\
\hline 0.30 & 1.10 & 1.25 & 1.35 & 1.55 & 1.55 \\
\hline 0.50 & 1.61 & 1.61 & 1.89 & 1.56 & 1.89 \\
\hline 0.70 & 1.52 & 1.33 & 1.45 & 1.46 & 1.52 \\
\hline 0.90 & 1.24 & 1.10 & 1.35 & 1.29 & 1.35 \\
\hline 1.10 & 1.09 & - & 1.13 & 1.07 & 1.13 \\
\hline
\end{tabular}

\subsection{Bending moment in the horizontal direction}

Of the three different ways used to analyze the bending moment in the vertical direction, only simulation with the mesh model is able to detect the increase in the bending moment in the horizontal direction. In no analyzed case was there detected a bending moment on the horizontal with significant values.

Figures 15 and 16 show the displacements and diagram of a horizontal bending moment for cases $P P 19$ and $P P 21$. These cases were chosen to demonstrate that there were no bending moments on the horizontal because they presented a huge difference in the maximum displacements of the vertical bars when they were analyzed by the isolated bar model. When they were analyzed with the mesh model, the maximum displacement values were the same as for all bars, as can be seen in Figures 9 and 10, suggesting that in such cases the horizontal bars should undergo greater forces to be able to equal the maximum displacements in all vertical bars.

In Figures 15 and 16 the bending moments in a horizontal direction are seen to be zero. Although the bending moment diagram is not presented in the three-dimensional models, it is possible to conclude that in those models the bending moments are also zero because, as can be seen in Figure 11, the horizontal displacement values are practically equal throughout a cross section, showing that there is no curvature on the horizontal. The fact there is no curvature on the horizontal means that the moment in the horizontal direction is zero. 


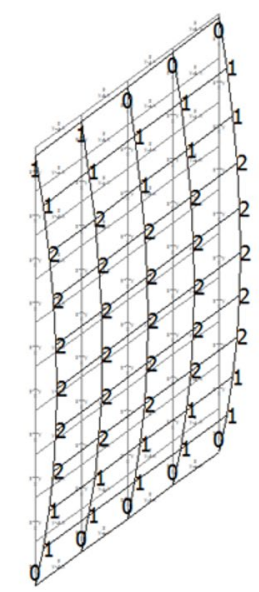

(a) Displacement (mm)

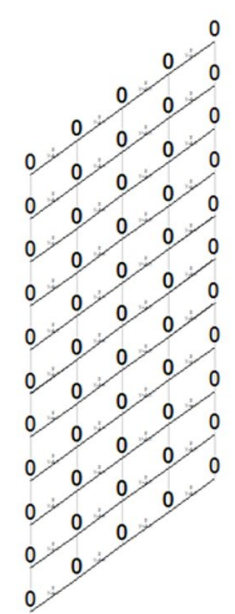

(b) Bending moment on the horizontal $(\mathrm{kN} \cdot \mathrm{m})$

Figure 15. Case $P P 19\left(\lambda=80 ; \mu_{b d}=0.020\right)-$ Mesh model

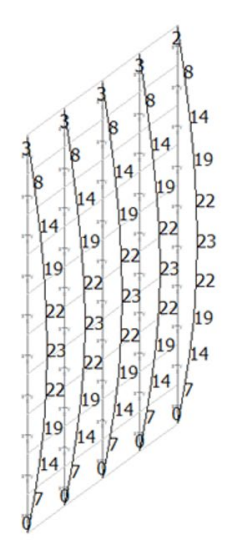

a) Displacement (mm)

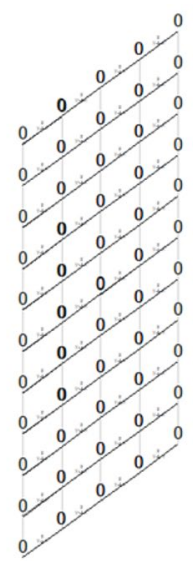

(b) Bending moment on the horizontal $(\mathrm{kN} \cdot \mathrm{m})$

Figure 16. Case $P P 21\left(\lambda=90 ; \mu_{b d}=0.029\right)-$ Mesh model

\section{CONCLUSIONS}

The principal conclusions from this study are:

The specifications for shear wall design in Brazil are quite different from the specifications for shear wall design in other countries of the Americas, Europe, Asia and Oceania, especially in relation to the loading forces. In most of these countries, shear walls must withstand seismic loads, while in Brazil most of its territory lies in a region where these loads are negligible.

Both the 3D model and the computer model consisting of a mesh of bars behaved properly. Therefore, the mesh model can be a good alternative for simulating shear walls, since its implementation is much simpler than that of the $3 \mathrm{D}$ model, in addition to requiring less computational effort. In this study, the computational effort was not of significant importance since isolated only one-floor shear walls were analyzed, however this may be a relevant factor when simulating an entire building.

The second order effects (local and localized) are negligible in the cases where slenderness is low, close to the limit of $\lambda=35$, confirming the ABNT NBR 6118:2014 recommendation to neglect these effects when the slenderness is equal to or less than 35 .

The localized second order effects are strongly influenced by the slenderness, normal force and bending moment around the axis with greater inertia, but these effects are no influenced by the ratio between the cross section dimensions. 
The values of the localized second order effects obtained from the mesh model are relatively low for the large majority of cases. The maximum values obtained for the ratio $M_{d} / M_{d, C O L U M N}$ using this model were: 1.06 for the cases where $v_{d}=0.1 ; 1.21$ for the cases where $v_{d}=0.3 ; 1.13$ for the cases where $v_{d}=0.5 ; 1.08$ for cases where $v_{d}=0.7 ; 1.07$ for the cases where $v_{d}=0.9 ; 1.05$ for cases where $v_{d}=1.1$.

The approximate process of ABNT NBR 6118:2014 provided much higher values for the localized second order effects that those obtained from the mesh model. The maximum values for the ratio $M_{d} / M_{d, \text { COLUMN }}$ with the approximate process of ABNT NBR 6118:2014 were: 1.07 for cases where $v_{d}=0.1 ; 1.55$ for cases where $v_{d}=0.3 ; 1.89$ for cases where $v_{d}=0.5 ; 1.52$ for cases where $v_{d}=0.7 ; 1.35$ for cases where $v_{d}=0.9$; and 1.13 for cases where $v_{d}=1.10$.

Regarding the consideration of the bending moment in the horizontal direction in shear walls with a rectangular section, bending moment in this direction was not observed in all cases analyzed. The results suggest that, in the case of shear walls with rectangular cross sections, there is no significant horizontal bending.

\section{ACKNOWLEDGMENTS}

The authors thank the Federal University of Pernambuco (UFPE), Piaui State University (UESPI) and the Federal Institute of Piauí (IFPI) for the opportunity they offered and for providing the necessary conditions to enable this study. They also thank TQS for the support in adapting a software version the requirements of this research.

\section{REFERENCES}

[1] Associação Brasileira de Normas Técnicas, Projeto de Estruturas de Concreto - Procedimento, NBR 6118, 2014.

[2] American Concrete Institute, Building Code Requirements for Structural Concrete, ACI-318, 2014.

[3] International Federation for Structural Concrete, Model Code, 2010.

[4] M. C. B. N. Campos, “Análise numérica de pilares-parede de concreto armado com seção retangular,” Ph.D. dissertation, Univ. Fed. Pernambuco, Recife, 2016.

[5] J. W. Wallace and J. P. Moehle, "Behavior and design of structural walls - lessons from recent laboratory tests \& earthquakes," in Int. Symp. Eng. Lesson Learn. 2011 Great East Earthq., 2012.

[6] J. H. Thomsen 4th and J. W. Wallace, "Displacement-based design of slender reinforced concrete structural walls - experimental verification," J. Struct. Eng., vol. 130, no. 4, pp. 618-630, 2004.

[7] P. F. Parra and J. P. Moehle, "Lateral buckling in reinforced concrete walls," in 10NCEE - Tenth U.S. Nat. Conf. Earthq. Eng., 2014.

[8] J. K. Wight and J. G. MacGregor, Reinforced Concrete: Mechanics and Design, 5th ed. New Jersey: Pearson Prentice Hall, 2009.

[9] J. M. Araújo, "Análise do processo aproximado da NBR-6118 para consideração dos efeitos localizados de segunda ordem," Rev. Teor. Prat. Eng. Civ., no. 10, pp. 1-10, 2007.

[10] R. L. S. França and A. E. Kimura, "Resultados de recentes pesquisas para o dimensionamento das armaduras longitudinal e transversal em pilares-parede," in An. $9^{\circ}$ Enc. Nac. Eng. Consult. Estrut., 2006.

[11] K. Arnott, "Shear wall analysis - new modelling, same answer," J. The Inst. Struct. Eng., vol. 83, no. 3, pp. 1-11, Feb 2005.

[12] S. Sritharan, J. Zhao, J. Waugh, S. Aaleti, Nonlinear Analysis of Rectangular and t-Shaped Concrete Walls. Ames: Dept. Civ. Constr. Environ. Eng., Iowa State Univ., 2008.

[13] Associação Brasileira de Normas Técnicas, Projeto de Estruturas Resistentes a Sismos - Procedimento, NBR 15421, 2006.

[14] Associação Brasileira de Normas Técnicas, Projeto de Estruturas de Concreto - Procedimento, NBR 6118, 2003.

[15] K. Ribeiro, “Diagramas para verificação de pilares retangulares em concreto armado submetidos à flexão composta normal,” M.S. thesis, Univ. Fed. Santa Catarina, Florianópolis, 2011.

[16] TQS Informática, CAD/TQS System - User's Handbook. São Paulo, 2010.

[17] MIDAS FEA, Nonlinear and Detail FE Analysis System for Civil Structures, Version 2.9.6, 2009.

[18] C. E. L. Melo, "Análise experimental e numérica de pilares birrotulados de concreto armado submetidos a flexo-compressão normal," Ph.D. dissertation, Univ. Brasília, Brasília, 2009.

Author contributions: This study is based on the doctoral thesis of the author M. C. B. N. Campos, who wrote it under the guidance of the authors P. M. V. Ribeiro and R. A. Oliveira.

Editors: Osvaldo Luís Manzoli, José Luiz Antunes de Oliveira e Sousa, Guilherme Aris Parsekian. 